University of Montana

ScholarWorks at University of Montana

$1-1999$

\title{
Males Feeding Females During Incubation. I. Required by Microclimate or Constrained by Nest Predation?
}

Thomas E. Martin

University of Montana - Missoula, tom.martin@umontana.edu

Cameron K. Ghalambor

Follow this and additional works at: https://scholarworks.umt.edu/wildbio_pubs

Part of the Life Sciences Commons

Let us know how access to this document benefits you.

\section{Recommended Citation}

Martin, Thomas E. and Ghalambor, Cameron K., "Males Feeding Females During Incubation. I. Required by Microclimate or Constrained by Nest Predation?" (1999). Wildlife Biology Faculty Publications. 29.

https://scholarworks.umt.edu/wildbio_pubs/29

This Article is brought to you for free and open access by the Wildlife Biology at ScholarWorks at University of Montana. It has been accepted for inclusion in Wildlife Biology Faculty Publications by an authorized administrator of ScholarWorks at University of Montana. For more information, please contact scholarworks@mso.umt.edu. 


\section{Males Feeding Females during Incubation. I. Required by Microclimate or Constrained by Nest Predation?}

\author{
Thomas E. Martin ${ }^{1, *}$ and Cameron K. Ghalambor ${ }^{1,2, \dagger}$ \\ 1. U.S. Geological Survey Biological Resources Division, Montana \\ Cooperative Wildlife Research Unit, Avian Studies Program, \\ University of Montana, Missoula, Montana 59812; \\ 2. Montana Cooperative Wildlife Research Unit and Division of \\ Biological Sciences, University of Montana, Missoula, Montana \\ 59812
}

Submitted March 17, 1998; Accepted July 24, 1998

AвsтRACт: Nest attentiveness (percentage of time spent on the nest) during incubation represents a parent-offspring conflict; incubating birds must balance a trade-off between caring for embryos by staying on the nest versus caring for themselves by getting off the nest to forage. For species in which females are the sole incubator, males can potentially affect this trade-off and increase nest attentiveness by feeding incubating females on the nest (incubation feeding). Increased nest attentiveness may be required when local microclimate conditions are harsh and thereby require greater incubation feeding (microclimate hypothesis). Alternatively, incubation feeding may be constrained by risk of attracting nest predators (nest predation hypothesis), which in turn may constrain female nest attentiveness because of energy limitation. We show that incubation feeding rates are much greater among cavity-nesting than among coexisting opennesting birds. Under the microclimate hypothesis, the greater incubation feeding rates of cavity-nesting birds generate the prediction that microclimate should be harsher than for open-nesting birds. Our results reject this hypothesis because we found the opposite pattern; cavity-nesting birds experienced more moderate (less variable) microclimates that were less often below temperatures (i.e., $16^{\circ} \mathrm{C}$ ) that can negatively impact eggs compared with open-nesting species. In contrast, incubation feeding rates were highly negatively correlated with nest predation both within and between the two nest types, supporting the nest predation hypothesis. Incubation feeding in turn was positively correlated with nest attentiveness. Thus, nest predation may indirectly affect female incubation behavior by directly affecting incubation feeding by the male.

Keywords: incubation feeding, indirect effects, nest attentiveness, incubation behavior, nest predation, microclimate.

\footnotetext{
* E-mail: tmartin@selway.umt.edu.

† E-mail: camerong@selway.umt.edu.
}

Am. Nat. 1999. Vol. 153, pp. 131-139. (c) 1999 by The University of Chicago. 0003-0147/99/5301-0010\$03.00. All rights reserved.
Avian embryos can suffer fitness costs such as increased mortality and reduced developmental rate with decreasing nest attentiveness (percentage of time that a parent sits on the nest) during incubation (White and Kinney 1974; Carey 1980; Lyon and Montgomerie 1985). Thus, high attentiveness should be a preferred state, possibly being somewhat relaxed in species with well-insulated nests (White and Kinney 1974). However, incubating birds are often constrained in their nest attentiveness because of limited energy resources (White and Kinney 1974; Martin 1987). Indeed, many birds require short recesses from the nest to obtain exogenous food resources to allow continued incubation. In the many species in which females incubate alone, males may reduce recesses and increase attentiveness by bringing food to incubating females and supplementing their energy resources. Such incubation feeding has been reported in a wide diversity of bird taxa (Lack 1940; Kendeigh 1952; Silver et al. 1985), and intraspecific studies have shown that greater incubation feeding can yield increased attentiveness (von Haartman 1958; Lyon and Montgomerie 1985; Lifjeld and Slagsvold 1986; Halupka 1994). Yet the influence of incubation feeding on nest attentiveness across species is unexamined despite the fact that incubation feeding rates and nest attentiveness vary extensively across species (e.g., Kendeigh 1952; Silver et al. 1985).

Given the fitness benefits of being attentive and the potential ability of incubation feeding to increase attentiveness, then an important question centers on why species vary in their rate of incubation feeding. One hypothesis suggests that greater incubation feeding is required in harsher microclimates to allow increased attentiveness because the fitness costs of leaving eggs unattended is greater (Lifjeld et al. 1987; Lyon and Montgomerie 1987; Nilsson and Smith 1988; Smith et al. 1989). Under this microclimate hypothesis, nest attentiveness and incubation feeding rates should be highest in species using nest sites that are exposed to extreme temperatures that can threaten embryo survival or reduce embryo developmental rates (Webb 1987; Haftorn 1988). An optimal temperature for embryo development is near $37^{\circ} \mathrm{C}$ for passerines, but they may 
tolerate short exposures to temperatures between $16^{\circ}$ and $41^{\circ} \mathrm{C}$, whereas temperatures outside this range affect embryo development and survival (Webb 1987). Indeed, Lyon and Montgomerie (1985) decreased nest attentiveness in female snow buntings (Plectrophenax nivalis) by removing male incubation feeding, which caused longer developmental (incubation) periods and increased mortality in an arctic environment where air temperatures often fell below $16^{\circ} \mathrm{C}$. Similarly, both Haftorn (1983) and Nilsson and Smith (1988) found reduced developmental rate and increased mortality when air temperatures fell below $16^{\circ} \mathrm{C}$. Thus, both incubation feeding and nest attentiveness should increase in species with nest sites where ambient temperatures increasingly fall outside of the $16^{\circ}-41^{\circ} \mathrm{C}$ range.

An alternative hypothesis is that incubation feeding is always advantageous but that it is constrained by nest predation; increased trips to the nest are hypothesized to attract attention of predators and increase predation risk for species that are more vulnerable to predation (i.e., Skutch 1949; Lyon and Montgomerie 1987; Weathers and Sullivan 1989; Martin 1992, 1996). Females can obtain more food in one foraging trip off the nest than a male can bring in one trip, so number of trips to the nest can be reduced by the female largely obtaining food herself. Under the nest predation hypothesis, species with higher risk of nest predation should show increased foraging by females and lower rates of incubation feeding by males.

Open- versus cavity-nesting bird species highlight these two alternative hypotheses. Incubation feeding is thought to be more prevalent in cavity- than open-nesting species (Lack 1940; Lyon and Montgomerie 1987). If incubation feeding is greater in cavity-nesting species, the pattern could be explained by predation risk because nest predation is generally less of a threat for cavity-nesting than for open-nesting birds in North America (Lack 1968; Ricklefs 1969; Martin and Li 1992; Martin 1995). Yet nest predation varies extensively within these groups (see Martin 1995), and cavities may also differ from open nests in other characteristics, such as microclimate (Lyon and Montgomerie 1987). Thus, both hypotheses are viable and need testing.

Here we examine these two hypotheses and the assumption that species with greater rates of incubation feeding exhibit greater nest attentiveness. We conduct our tests among coexisting species because they experience the same general predator assemblage and the same macroclimate. The latter is important because any differences in nesting microclimate can then be attributed to nest site effects. We also include data on three coexisting species in a different geographic location to examine the fit of species from alternative sites.

\section{Study Area and Methods}

Study sites for the main suite of species were snowmelt drainages located on the Mogollon Rim in central Arizona at approximately 2,600 m elevation. These drainages are mixed deciduous-conifer forests (see Martin 1998 for a detailed description). Study sites for three species were in western Montana in the Bitterroot National Forest in riparian drainages comprised primarily of deciduous trees (Tewksbury et al. 1998).

Red squirrels (Tamiasciurus hudsonicus), chipmunks (Eutamias spp.), long-tailed weasels (Mustela frenata), house wrens (Troglodytes aedon), and Steller's jays (Cyanocitta stelleri) were present as possible nest predators in both study systems. General observations and photographic records of predation events indicate that red squirrels and chipmunks were the primary predators (Martin 1988, 1993; Tewksbury et al. 1998).

Twenty study drainages were searched for bird nests from May 1 to July 31 from 1986 to 1996. We located nests by observing parental behavior and following them to nest sites, and then we monitored nests intensively to determine fate (described in Martin and Geupel 1993; Martin et al. 1996; Martin 1998). Nest predation was calculated only for the incubation period for the hypotheses tested here. Nests that hatched young were considered successful. Predation was assumed when the eggs disappeared. Most nests were found before onset of incubation, but some nests were not, and so nest predation was calculated using the Mayfield method (Mayfield 1975; Hensler and Nichols 1981). We pooled nests across years to estimate generalized nest predation rates based on extensive samples (appendix) that may reflect selection over long periods and not year-specific anomalies.

From 1993 to 1997, incubating birds were videotaped for the first $6 \mathrm{~h}$ of the day, beginning $0.5 \mathrm{~h}$ before sunrise (starting at ca. 5:30 A.M. PST and ending at ca. 11:30 A.M. PST). This protocol standardized both time of day and sampling duration and allowed the most rigorous estimation of rates for species with very low rates because incubation feeding was most frequent in the morning. Videotapes were scored back in the lab for number of male feeds and for nest attentiveness, measured as the percentage of the $6 \mathrm{~h}$ that females sat on the nest. Video cameras contained a $20 \times$ zoom, which allowed clear quantification of incubation feeding. Nests were the sampling unit such that mean feeds/h and percentage of time on the nest were averaged across all nests that were sampled to obtain the mean and standard error for incubation feeding rate and nest attentiveness for each species. Videotaping focused on some species for various other reasons, causing high sample sizes for these species, but a 
minimum of six individuals $(36 \mathrm{~h})$ were taped for each species used here (appendix).

We measured microclimate (temperature) using Onset Hobo data loggers. We placed temperature probes $2 \mathrm{~cm}$ above the head of the incubating bird for both open- and cavity-nesting birds, and we measured temperature at 5min intervals for $5 \mathrm{~d}$ for individuals of a subset of species of each nest type. We measured temperatures during five periods in 1996 (start dates = June 11, 16, 21, and 27, and July 1) and three in 1997 (start dates = May 31, June 6 , and June 25). For each start date, we paired open- and cavity-nesting species to control for date effects. To check possible nest insulation effects, we also conducted three paired comparisons in June 1998 between open- and cavity-nesting birds, where we inserted temperature probes in the bottom lining of the nest but not in contact with the female.

Analyses were based on comparisons across species. Phylogenetic relationships potentially create a problem of nonindependence among species because closely related species may exhibit similar traits (Felsenstein 1985; Harvey and Pagel 1991; Martins and Garland 1991). As a result, we analyzed the data using the independent contrast method of Felsenstein (1985) and incorporating the methods of Purvis and Garland (1993) for incompletely resolved phylogenies, based on software described by Purvis and Rambaut (1995). We constructed the phylogenetic hypothesis on the basis of the most recent information available for North America as described in Martin and Clobert (1996). We did not have consistent estimates of branch lengths because data came from different studies using differing methods and data were lacking for many branches. As a result, branch lengths were set as equal, reflecting a speciational model, and also were estimated using techniques described by Grafen (1989) and Pagel (1992). Analyses using these differing branch length estimates yielded equivalent results in terms of statistical significance, but examination of branch length diagnostics (see Garland et al. 1992) indicated that equal branch lengths were the most appropriate; absolute values of contrasts were not related $(P>.05)$ to their standard deviations for any trait when branch lengths were set as equal. All regressions using independent contrasts were based on forcing the regression line through the origin (see Garland et al. 1992). In all cases, analyses of raw data are provided at the same time as analyses of phylogenetically corrected data to allow illustration of actual species values.

We tested potential allometric effects of body mass on incubation behaviors (i.e., Williams 1991, 1996) using logtransformed body mass from Dunning (1984). We conducted comparisons among nest types using one-way ANOVA, followed by Tukey's post hoc tests. We also tested differences in incubation behaviors among species with and without dichromatism because dichromatism may reflect male investment (Darwin 1871; Promislow et al. 1992; Andersson 1994). For percentage data (nest predation rate, attentiveness, percentage of time temperature is below certain levels), analyses were conducted on arcsine-transformed data, but raw data are reported to allow ease of interpretation. We used simple Pearson correlations to examine bivariate relationships and Pearson partial correlations $\left(r_{\mathrm{p}}\right)$ to control collinearities in relationships.

\section{Results}

Neither incubation feeding rates $(r=-0.17, P=.48)$ nor nest attentiveness $(r=-0.27, P=.26)$ were correlated with log-transformed body mass. Also, neither incubation feeding rates $(F=0.08, P=.78)$ nor nest attentiveness $(F=0.03, P=.86)$ differed between monochromatic and dichromatic species. Incubation feeding rates were clearly greater $(F=50.7, P<.0001)$ for cavity- than for opennesting species (fig. 1). Incubation feeding rates also differed among excavators, nonexcavators, and open nesters $(F=69.0, P<.0001$; see fig. 1$)$. The feeding rates of excavators were greater than those of nonexcavators (Tukey's test, $P=.001$ ), and the feeding rates of nonexcavators were greater than those of open nesters (Tukey's test, $P<.001$ ). Nest attentiveness (see fig. 2) also differed among nest types $(F=36.2, P<.0001)$, but nonexcavators did not differ from excavators (Tukey's test, $P=.90$ ), whereas both differed from open nesters (Tukey's test, $P<.001$ ).

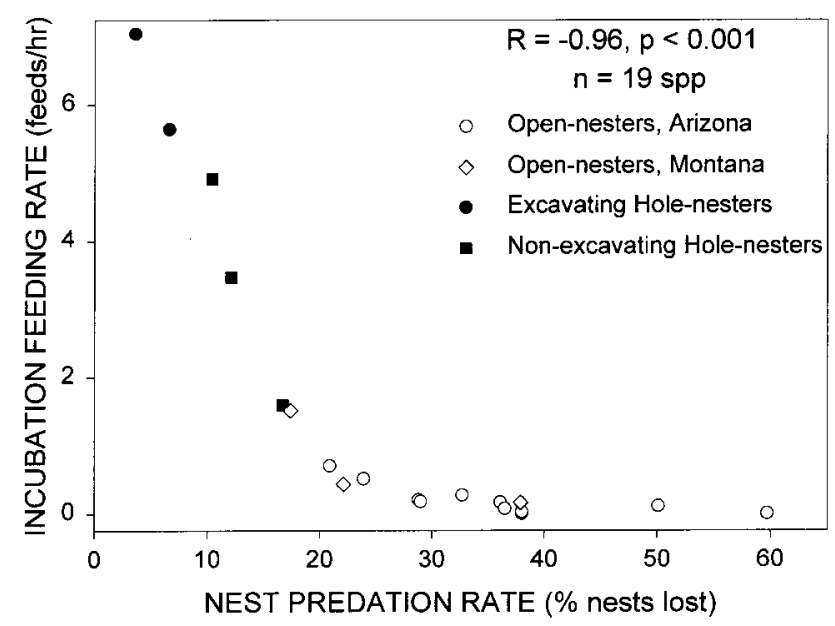

Figure 1: Incubation feeding rates (number of feeds per hour) relative to nest predation rate (percentage of nests lost to predators). Sample sizes are provided in the appendix. The relationship between incubation feeding and nest predation within each nest type is significant: open-nesting species: $R=-0.91, P<.0001$; cavity-nesting species: $R=-0.98, P=.001)$. 


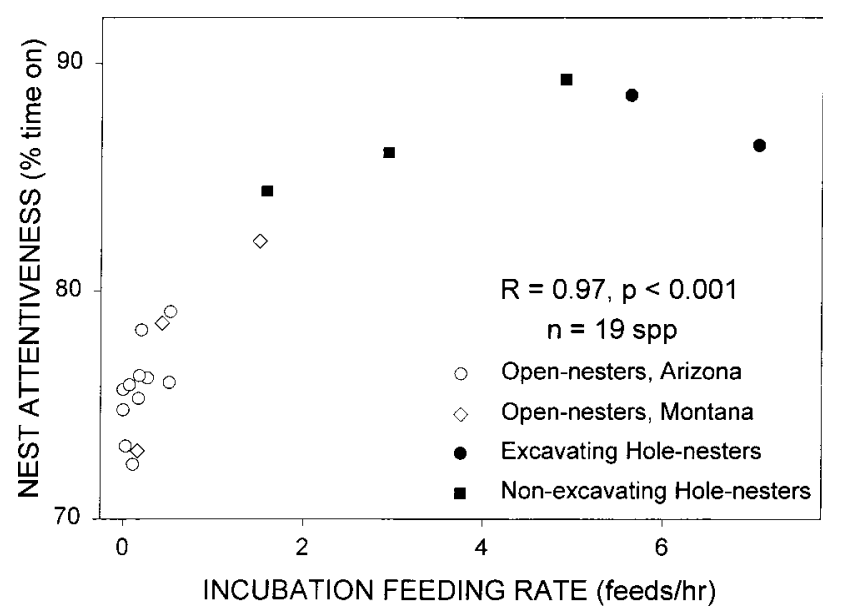

Figure 2: Nest attentiveness (percentage of time that the female is incubating on the nest) relative to the rate that males bring food to the nest (incubation feeding). The relationship across all 19 species of both nest types is curvilinear (see "Results") and significant as shown. Diamonds represent the species studied in Montana, and circles and squares represent the species studied in Arizona. Open symbols represent open nesters, and solid symbols represent hole nesters, where solid squares are nonexcavators and solid circles are excavators.

A total of 4,046 nests were monitored to allow determination of nest predation during incubation for the 19 species (appendix). Incubation feeding rates were inversely correlated $(R=-0.96, P<.0001)$ with nest predation rates across species, but the relationship was curvilinear across all nest types (fig. 1$)$; the quadratic term $\left(b^{2}=\right.$ $39.8 \pm 5.98, t=6.67, P<.001)$ explained significant additional variation beyond the linear term $(b=-35.3 \pm$ 3.91, $t=-9.04, P<.0001)$. Incubation feeding was linearly correlated with nest predation within cavity nesters $(R=-0.978, P<.0001)$, whereas it was curvilinearly related in open nesters $(R=-0.911, P<.0001)$; the quadratic term explained additional variance $(t=4.58, P=$ $.001)$ beyond the linear $(t=-5.66, P<.0001)$. The correlation between incubation feeding and nest predation was also curvilinear when independent contrasts were used to control for phylogenetic effects $(R=0.74, P<.0001$, $n=18$ contrasts); the quadratic term explained additional variance $(t=4.13, P=.001)$ beyond the linear term $(t=-4.227, P=.001)$.

Attentiveness was curvilinearly related to nest predation $(R=0.89, P<.0001)$; the quadratic term explained additional variance $(t=4.95, P=.001)$ beyond the linear $(t=-7.76, P<.0001)$. Incubation feeding showed an even stronger relationship $(R=0.97, P<.0001)$ with attentiveness (fig. 3), where the quadratic term $(t=-7.1, P<$ $.001)$ explained additional variance beyond the linear term $(t=10.8, P<.0001)$. Correlations of both nest predation and incubation feeding with attentiveness can be expected given that both are correlated with each other. When effects of incubation feeding were controlled, nest predation was still correlated with nest attentiveness $\left(r_{\mathrm{p}}=0.59\right.$, $P=.010)$. However, when effects of nest predation were controlled, incubation feeding was much more strongly correlated with nest attentiveness $\left(r_{\mathrm{p}}=0.83, P<.0001\right)$. Similar results were obtained when phylogeny was controlled using independent contrasts. Incubation feeding showed a curvilinear relationship with attentiveness ( $R=0.88, P<.0001, n=18$ contrasts); the quadratic term $(t=-7.23, P<.0001)$ explained additional variation beyond the linear term $(t=6.59, P<.0001)$. When incubation feeding and phylogeny were controlled, nest predation was not correlated with attentiveness $\left(r_{\mathrm{p}}=-0.14\right.$,
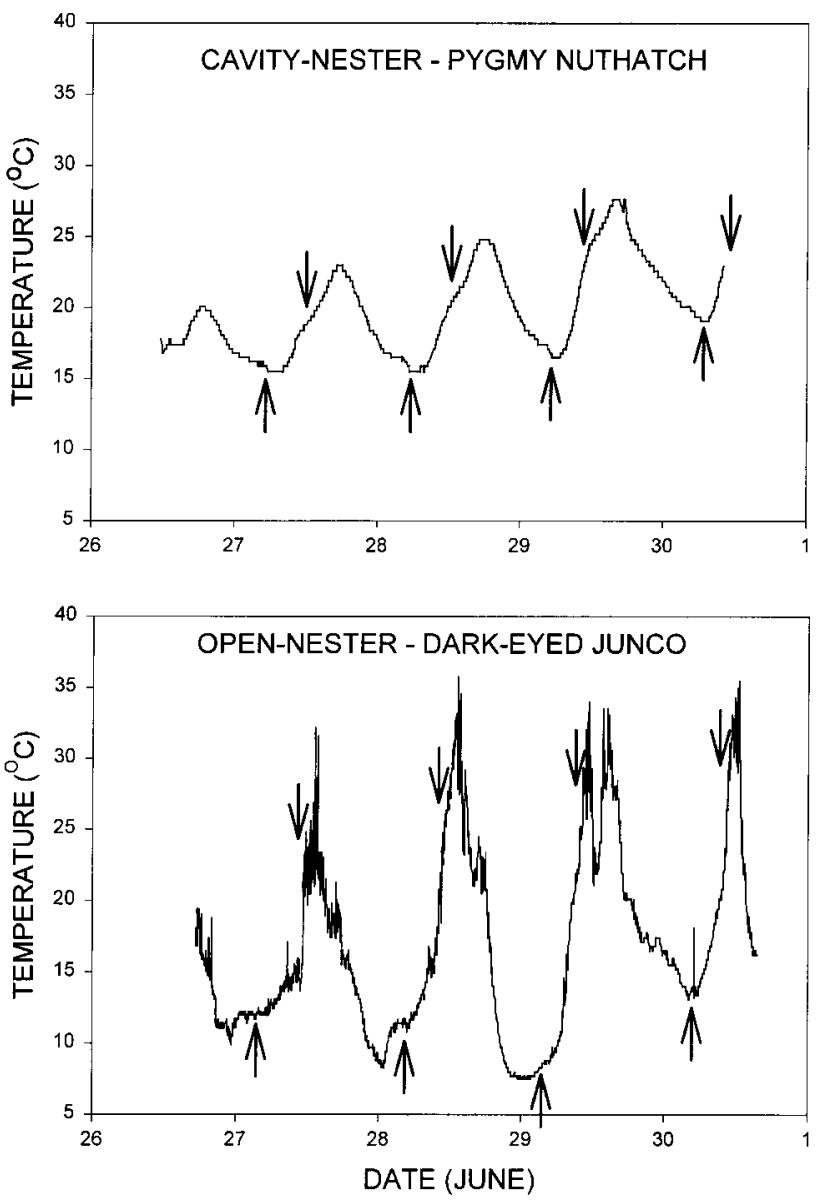

Figure 3: Temperature measured $2 \mathrm{~cm}$ above the head of incubating birds at 5-min intervals for cavity- and open-nesting birds to illustrate patterns for these two nest types (see table 1). Arrows indicate beginning and end of typical video-monitoring times. 
$P=.59)$. When nest predation and phylogeny were controlled, incubation feeding was still highly correlated with attentiveness $\left(r_{\mathrm{p}}=0.60, P<.014\right)$. Thus, nest predation appears to constrain incubation feeding and incubation feeding appears to influence nest attentiveness.

Temperature was measured for $5 \mathrm{~d}$ each at 40 nests (i.e., 200 total nest days), with measurements at 20 nests of eight open-nesting species and 20 nests of seven cavitynesting species. Nests, rather than nest days, were the sampling unit. Temperature measured at nest sites of opennesting species showed a greater range of variation than those of cavity-nesting species during both the entire 24$\mathrm{h}$ period and the video sampling period (table 1; fig. 3). As a result, open-nesting species experienced colder minimum temperatures and warmer maximum temperatures than cavity-nesting species (table 1). Moreover, open-nesting species experienced temperatures below $16^{\circ} \mathrm{C}$ during daylight hours substantially more often than cavity-nesting species (table 1). Open-nesting species also experienced temperatures above $41^{\circ} \mathrm{C}$ slightly more often than cavitynesting species, but this temperature range was infrequent (table 1). Finally, temperatures inside the nest bowls were consistently warmer in cavity than open nests in all three paired comparisons $(t>24, P<.001$ in all three cases), with much more rapid cooling when the bird was off the nest for open nests (fig. 4).

\section{Discussion}

Studies of variation in nest attentiveness and incubation feeding have mostly examined these traits within individual species, focusing on the effects of microclimate on nutritional needs of incubating females (e.g., Lyon and

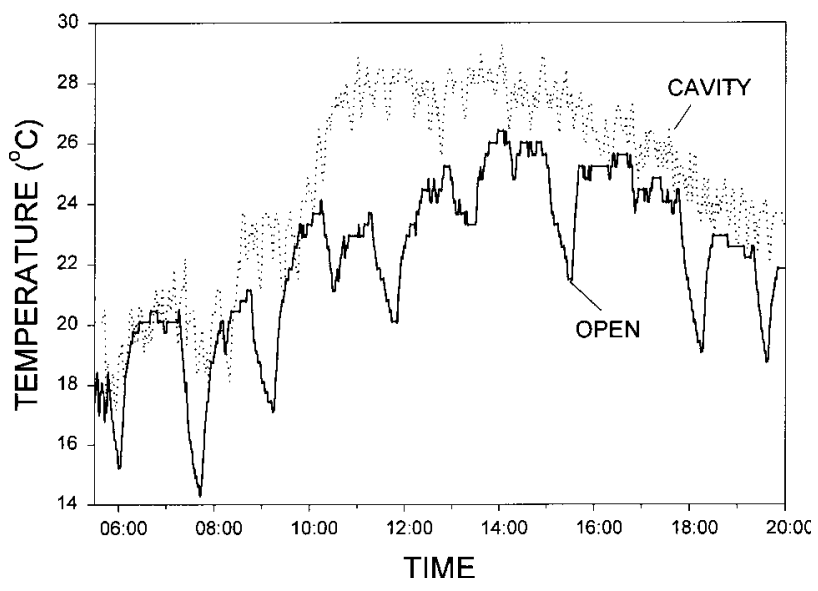

Figure 4: Temperature measured at 5-min intervals in the bottom of the nest bowl to examine possible differences of nest insulation and convective air currents for cavity- and open-nesting birds. Downward spikes represent female off-bouts.

Montgomerie 1985, 1987; Lifjeld and Slagsvold 1986; Lifjeld et al. 1987; Nilsson and Smith 1988; Smith et al. 1989; Halupka 1994). These intraspecific studies primarily test proximate responses of individuals to temperature and food availability. Here we examined variation among coexisting species to gain insight into evolution of incubation behaviors. Our results provide the first evidence to suggest that evolution of variation in incubation feeding rates may have been constrained by nest predation; incubation feeding was strongly inversely correlated with variation in nest predation among species within each nest type as well as between open- and cavity-nesting species. Moreover, in-

Table 1: Mean $( \pm S E)$ maximum and minimum temperatures, the range in temperature, and the percentage of time that temperature was below $16^{\circ}$ or above $41^{\circ} \mathrm{C}$ for open- ( $n=20$ nests) and cavity-nesting ( $n=20$ nests) bird species

\begin{tabular}{lrcrc}
\hline & Open & Cavity & \multicolumn{1}{c}{$F$} & \multicolumn{1}{c}{$P$} \\
\hline 24 h: & & & & \\
Maximum temperature $\left({ }^{\circ} \mathrm{C}\right)$ & $37.9(1.8)$ & $31.3(1.3)$ & 8.5 & .006 \\
Minimum temperature $\left({ }^{\circ} \mathrm{C}\right)$ & $6.9(.8)$ & $15.0(1.0)$ & 39.2 & .000 \\
Range & $31.1(1.9)$ & $16.3(1.1)$ & 44.1 & .000 \\
Time $<16^{\circ} \mathrm{C}(\%)$ & $51.0(3.6)$ & $9.7(2.9)$ & 79.4 & .000 \\
Time $\geq 411^{\circ} \mathrm{C}(\%)$ & $1.2(.6)$ & $.05(.05)$ & 4.1 & .050 \\
Video hours $(5: 30-11: 30$ A.M. $):$ & & & & \\
Maximum temperature $\left({ }^{\circ} \mathrm{C}\right)$ & $33.1(1.2)$ & $30.6(1.5)$ & 1.1 & .31 \\
Minimum temperature $\left({ }^{\circ} \mathrm{C}\right)$ & $7.9(.8)$ & $17.9(1.2)$ & 44.7 & .000 \\
Range & $25.2(1.8)$ & $12.7(1.2)$ & 33.0 & .000 \\
Time $<16^{\circ} \mathrm{C}(\%)$ & $38.4(5.0)$ & $16.9(4.2)$ & 11.0 & .002 \\
Time $\geq 411^{\circ} \mathrm{C}(\%)$ & $2.3(1.3)$ & $.0(.0)$ & 3.2 & .080 \\
\hline
\end{tabular}

Note: Temperatures were measured every $5 \mathrm{~min}$ for $5 \mathrm{~d}$ at each nest (see fig. 4), and data summarized here are for $24 \mathrm{~h}$ and hours of video observations (5:30-11:30 A.M.). 
cubation feeding, in turn, was strongly correlated with nest attentiveness across species. Because we examined coexisting species, differences among species should not reflect phenotypic adjustments to encounter rate with predators near the nest because such encounter rates are similar. Indeed, predators were rarely seen or heard near the nest on videos (T. E. Martin and C. K. Ghalambor, personal observation). Moreover, experimental presentation of predators shows that adjustments are short term and occur only in the presence of a predator; feeding rates quickly return to higher baseline levels when the predator is gone (C. K. Ghalambor and T. E. Martin, unpublished data). Thus, our results suggest that nest predation indirectly influences female attentiveness by directly affecting male incubation feeding.

The conclusion that nest predation is constraining incubation feeding, which then affects nest attentiveness (nest predation $\rightarrow$ incubation feeding $\rightarrow$ nest attentiveness), is supported by several patterns. First, when effects of incubation feeding were controlled statistically, nest predation was not correlated with attentiveness, whereas incubation feeding was correlated with attentiveness even when effects of nest predation were controlled statistically. Moreover, if nest predation acted on female patterns alone, then increased nest predation should favor increased attentiveness, particularly in nest sites with exposed eggs; females sitting on the nest make the eggs and nest more cryptic (Westmoreland and Best 1986), and females are able to defend the nest against predators more rapidly and readily if they are on the nest to see approaching predators (see Montgomerie and Weatherhead 1988; Martin 1992). However, attentiveness was greater in cavity nesters, where predation rates are low and eggs are already cryptic inside nest cavities. The greater attentiveness of cavity nesters can be explained more easily by their greater incubation feeding rates (fig. 3 ), and variation in incubation feeding is explained by nest predation (fig. 2). Finally, the variation exists within each nest type, which indicates that the patterns are not simply due to differences between nest types. Of course, some feedback may exist where species that can afford to increase their incubation feeding because of lowered nest predation may obtain even lower nest predation from the resulting increase in attentiveness.

These data argue against the importance of microclimate in driving variation in incubation feeding across species. Temperatures on our study sites rarely reach above lethal levels (see table 1), so birds primarily have to respond to cold temperatures at our high elevations. Colder air causes reductions in egg temperatures even when the female sits on the eggs (see Haftorn 1983; Webb 1987), but eggs cool even more when females get off the nest to forage. Reductions in average egg temperature by as little as $1^{\circ} \mathrm{C}$ can have a negative impact on both embryo development rate and survival (Haftorn 1983). Eggs cool faster at colder temperatures such that parents should obtain greater fitness benefits from increased incubation feeding and female attentiveness at increasingly colder temperatures. Indeed, removal of male incubation feeding in snow buntings caused decreased nest attentiveness and decreased embryo development in an environment with temperatures similar to ours (Lyon and Montgomerie 1985). Lyon and Montgomerie (1987) argued that snow buntings that nest in rock cavities exhibit greater incubation feeding than coexisting Lapland longspurs because snow buntings suffer colder temperatures. Yet, nest predation was also reduced in snow buntings compared with Lapland longspurs (see Lyon and Montgomerie 1987), so their results also could be explained by nest predation. Nonetheless, they suggested that cavity-nesting birds may exhibit greater incubation feeding than open-nesting birds in general because cavities get less exposure to the warming effects of sunlight. We found, in contrast, that opennesting birds suffered colder temperatures and for longer durations than cavity-nesting birds (table 1; fig. 3). Moreover, the cooling effects of a given temperature on eggs may be exacerbated in open nests compared with cavity nests because the exposed nature of open nests makes them subject to increased cooling from convective air currents (see Zerba and Morton 1983). Indeed, we found temperature inside the nest bowl to be consistently warmer in cavity nests than in open nests, with much colder spikes when the nest is unattended in open nests (fig. 4). Thus, the microclimate hypothesis predicts open-nesting species should exhibit higher incubation feeding during morning hours on the basis of our measured temperature differences (see table 1). We found the opposite results (i.e., fig. 2), which caused us to reject this hypothesis.

Additional evidence arguing against microclimate driving variation in incubation feeding rates comes from species that nest in the middle of summer in North America, when it is least likely to get cold; such species, like American goldfinch (Spinus tristis) and cedar waxwing (Bombycilla cedrorum), still exhibit high rates of incubation feeding (Kendeigh 1952). In contrast, many ground-nesting warblers (Parulidae) that nest early in the year, when it is very cold, exhibit little incubation feeding (fig. 1). Of course, microclimate may become increasingly important in harsher climatic environments, such as the Arctic, as found by Lyon and Montgomerie (1987). Nonetheless, our results suggest that in temperate areas the causal arrows are reversed. Instead of microclimate requiring increased attentiveness, which then requires increased incubation 
feeding (microclimate $\rightarrow$ nest attentiveness $\rightarrow$ incubation feeding), we suggest that over evolutionary time nest predation constrains incubation feeding, which in turn constrains attentiveness (nest predation $\rightarrow$ incubation feeding $\rightarrow$ nest attentiveness). In other words, food (or energy) limitation and nest predation interact (Martin 1992) with each other; energy limits female nest attentiveness and nest predation exacerbates this food limitation by constraining male help.

In sum, incubation feeding varies widely among species and has an important influence on nest attentiveness. Prior studies have focused on proximate effects of microclimate and food limitation on variation in incubation feeding and nest attentiveness within species, while comparative studies testing ultimate sources of variation across species have been ignored. Our results indicate that incubation feeding is beneficial (i.e., allows increased nest attentiveness) but that costs of nest predation may play a pivotal role in placing constraints on the rate of incubation feeding evolved among species.

\section{Acknowledgments}

We appreciate many helpful suggestions made by J. Lifjeld, B. Lyon, and three anonymous reviewers. We thank many field assistants for help in collecting the field data. We also thank the Arizona Game and Fish Department, the Blue Ridge Ranger Station of the Coconino National Forest, and the Apache-Sitgreaves National Forest for their support of this work. This study was supported by grants from the National Science Foundation (DEB-9407587, DEB-9527318, IBN-9701116, DEB-9707598) and the BBIRD (Breeding Biology Research and Monitoring Database) program under the Global Change Research Program of the Biological Resources Division.

\section{APPENDIX}

Table A1: List of study species, sample sizes (number of nests) studied for predation and incubation feeding, and presence $(+)$ or absence (o) of dichromatism

\begin{tabular}{|c|c|c|c|}
\hline & Nest predation & Incubation feeding & Dichromatism \\
\hline \multicolumn{4}{|l|}{ Open-nesting species: } \\
\hline Cordilleran flycatcher Empidonax difficilis & 272 & 8 & o \\
\hline Dusky flycatcher Empidonax oberholseri ${ }^{\mathrm{a}}$ & 115 & 6 & o \\
\hline Hermit thrush Catharus guttatus & 369 & 9 & o \\
\hline American robin Turdus migratorius & 224 & 17 & + \\
\hline Orange-crowned warbler Vermivora celata & 394 & 82 & o \\
\hline Virginia's warbler Vermivora virginiae & 189 & 51 & o \\
\hline Yellow-rumped warbler Dendroica coronata & 140 & 8 & + \\
\hline Yellow warbler Dendroica petechia ${ }^{\mathrm{a}}$ & 332 & 20 & + \\
\hline MacGillivray's warbler Oporornis tolmiei & 83 & 10 & + \\
\hline American redstart Setophaga ruticilla ${ }^{\mathrm{a}}$ & 92 & 7 & + \\
\hline Red-faced warbler Cardellina rubrifrons & 238 & 50 & + \\
\hline Western tanager Piranga ludoviciana & 123 & 10 & + \\
\hline Green-tailed towhee Pipilo chlorurus & 129 & 6 & o \\
\hline Dark-eyed junco Junco hyemalis & 369 & 8 & o \\
\hline \multicolumn{4}{|l|}{ Cavity-nesting species: } \\
\hline Mountain chickadee Parus gambeli & 277 & 13 & o \\
\hline White-breasted nuthatch Sitta carolinensis & 80 & 8 & o \\
\hline Red-breasted nuthatch Sitta canadensis & 294 & 24 & + \\
\hline Pygmy nuthatch Sitta pygmaea & 255 & 14 & o \\
\hline Brown creeper Certhia americana & 66 & 13 & o \\
\hline
\end{tabular}

\footnotetext{
${ }^{\mathrm{a}}$ Indicates species studied in Montana; data courtesy of J. Tewksbury.
} 


\section{Literature Cited}

Andersson, M. 1994. Sexual selection. Princeton University Press, Princeton, N.J.

Carey, C. 1980. The ecology of avian incubation. BioScience 30:819-824.

Darwin, C. 1871. The descent of man, and selection in relation to sex. J. Murray, London.

Dunning, J. B., Jr. 1984. Body weights of 686 species of North American birds. Western Bird Banding Association Monograph 1. Eldon, Cave Creek, Ariz.

Felsenstein, J. 1985. Phylogenies and the comparative method. American Naturalist 125:1-15.

Garland, T., Jr., P. H. Harvey, and A. R. Ives. 1992. Procedures for the analysis of comparative data using phylogenetically independent contrasts. Systematic Biology 41:18-32.

Grafen, A. 1989. The phylogenetic regression. Philosophical Transactions of the Royal Society London B, Biological Sciences 326:119-157.

Haftorn, S. 1983. Egg temperature during incubation in the great tit Parus major, in relation to ambient temperature, time of day, and other factors. Fauna Norvegica Series C, Cinclus 6:22-38.

- 1988. Incubating female passerines do not let egg temperature fall below the "physiological zero temperature" during their absences from the nest. Ornis Scandinavica 19:97-110.

Halupka, K. 1994. Incubation feeding in meadow pipit Anthus pratensis affects female time budget. Journal of Avian Biology 25:251-253.

Harvey, P., and M. D. Pagel. 1991. The comparative method in evolutionary biology. Oxford University Press, Oxford.

Hensler, G. L., and J. D. Nichols. 1981. The Mayfield method of estimating nesting success: a model, estimators and simulation results. Wilson Bulletin 93: 42-53.

Kendeigh, S. C. 1952. Parental care and its evolution in birds. Illinois Biological Monographs 22:1-357.

Lack, D. 1940. Courtship feeding in birds. Auk 57: 169-178.

- 1968. Ecological adaptations for breeding in birds. Methuen, London.

Lifjeld, J. T., and T. Slagsvold. 1986. The function of courtship feeding during incubation in the pied flycatcher Ficedula hypoleuca. Animal Behaviour 34:1441-1453.

Lifjeld, J. T., T. Slagsvold, and G. Stenmark. 1987. Allocation of incubation feeding in a polygynous mating system: a study on pied flycatchers Ficedula hypoleuca. Animal Behaviour 35:1663-1669.

Lyon, B. E., and R. D. Montgomerie. 1985. Incubation feeding in snow buntings: female manipulation or in- direct male parental care? Behavioral Ecology and Sociobiology 17:279-284.

- 1987. Ecological correlates of incubation feeding: a comparative study of high arctic finches. Ecology 68: 713-722.

Martin, T. E. 1987. Food as a limit on breeding birds: a life-history perspective. Annual Review of Ecology and Systematics 18:453-487.

- 1988. On the advantage of being different: nest predation and the coexistence of bird species. Proceedings of the National Academy of Sciences of the USA 85:2196-2199.

- 1992. Interaction of nest predation and food limitation in reproductive strategies. Current Ornithology 9:163-197.

- 1993. Nest predation and nest sites: new perspectives on old patterns. BioScience 43:523-532.

-1995. Avian life history evolution in relation to nest sites, nest predation and food. Ecological Monographs 65:101-127.

. 1996. Life history evolution in tropical and south temperate birds: what do we really know? Journal of Avian Biology 27:263-272.

- 1998. Are microhabitat preferences of coexisting species under selection and adaptive? Ecology 79: 656-670.

Martin, T. E., and J. Clobert. 1996. Nest predation and avian life history evolution in Europe versus North America: a possible role of humans? American Naturalist 147:1028-1046.

Martin, T. E., and G. R. Geupel. 1993. Nest-monitoring plots: methods for locating nests and monitoring success. Journal of Field Ornithology 64:507-519.

Martin, T. E., and P. Li. 1992. Life history traits of openversus cavity-nesting birds. Ecology 73:579-592.

Martin, T. E., C. R. Paine, C. J. Conway, and W. Hochachka. 1996. BBIRD field protocol. U.S. Geological Survey Biological Resources Division Report. http:// pica.wru.umt.edu/bbird.

Martins, E. P., and T. Garland, Jr. 1991. Phylogenetic analyses of the correlated evolution of continuous characters: a simulation study. Evolution 45:534-557.

Mayfield, H. 1975. Suggestions for calculating nest success. Wilson Bulletin 87:456-466.

Montgomerie, R. D., and P. J. Weatherhead. 1988. Risks and rewards of nest defense by parent birds. Quarterly Review of Biology 63:167-187.

Nilsson, J.-A., and H. G. Smith. 1988. Incubation feeding as a male tactic for early hatching. Animal Behaviour 36:641-647.

Pagel, M. D. 1992. A method for the analysis of comparative data. Journal of Theoretical Biology 156:431-442. Promislow, D. E. L., R. D. Montgomerie, and T. E. Martin. 
1992. Mortality costs of sexual dimorphism in birds. Proceedings of the Royal Society of London B, Biological Sciences 250:143-150.

Purvis, A., and T. Garland, Jr. 1993. Polytomies in comparative analyses of continuous characters. Systematic Biology 42:569-575.

Purvis, A., and A. Rambaut. 1995. Comparative analysis by independent contrasts (CAIC): an Apple Macintosh application for analysing comparative data. Computer Applications in the Biosciences 11:247-251.

Ricklefs, R. E. 1969. An analysis of nesting mortality in birds. Smithsonian Contributions to Zoology 9:1-48.

Silver, R., H. Andrews, and G. F. Ball. 1985. Parental care in an ecological perspective: a quantitative analysis of avian subfamilies. American Zoologist 25:823-840.

Skutch, A. F. 1949. Do tropical birds rear as many young as they can nourish? Ibis 91:430-455.

Smith, H. G., H. Kallander, J. Hultman, and B. Sanzen. 1989. Female nutritional state affects the rate of male incubation feeding in the pied flycatcher Ficedula hypoleuca. Behavioral Ecology and Sociobiology 24: 417-420.

Tewksbury, J. J., S. J. Hejl, and T. E. Martin. 1998. Landscape consequences for breeding success in western riparian habitats. Ecology (in press). von Haartman, L. 1958. The incubation rhythm of the female pied flycatcher (Ficedula hypoleuca) in the presence and absence of the male. Ornis Fennica 35:71-76.

Weathers, W. W., and K. A. Sullivan. 1989. Nest attentiveness and egg temperature in the yellow-eyed junco. Condor 91:628-633.

Webb, D. R. 1987. Thermal tolerance of avian embryos: a review. Condor 89:874-898.

Westmoreland, D., and L. B. Best. 1986. Incubation continuity and the advantage of cryptic egg coloration to mourning doves. Wilson Bulletin 98:297-300.

White, F. N., and J. L. Kinney. 1974. Avian incubation. Science (Washington, D.C.) 186:107-115.

Williams, J. B. 1991. On the importance of energy considerations to small birds with gynelateral intermittent incubation. Proceedings Acta XX Congressius Internationalis Ornithologici 20:1964-1975.

- 1996. Energetics of avian incubation. Pages 375-415 in C. Carey, ed. Avian energetics and nutritional ecology. Chapman \& Hall, New York.

Zerba, E., and M. L. Morton. 1983. Dynamics of incubation in mountain white-crowned sparrows. Condor 85:1-11. 